Military Technical College

Kobry El-Kobbah,

Cairo, Egypt

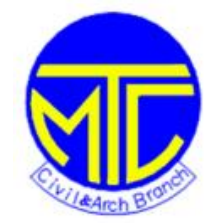

$9^{\text {th }}$ International Conference on Civil and Architecture Engineering

ICCAE-9-2012

\title{
TOWARDS A NEW VISION FOR SUSTAINABLE URBAN PARKS A CASE STUDY OF ALAIN WILDLIFE PARK IN ABU DHABI
}

\author{
Ghada Mohamed Rehan*
}

\begin{abstract}
The interest of all human societies with environment has grown recently especially after lifestyle associated with dangerous environmental crisis, such as loss of biodiversity and shrinking green space, air and water pollution, global w arming and the depletion of non-renewable resources, which prompted the call for a sustainable alternative model works to achieve harmony between the achievement of development objectives on the one hand and the protection of the environment and sustainabi lity on the other hand The UN Conference on Environment and Development include a set of criteria and indicators that reflect the positive outlook for the sustainability of human settlements development to create an environment based high -efficiency. Urban parks are considered one of the important mechanisms for achieving sustainable urban development from this standpoint this research focuses on the study of urban parks and their role in achieving sustainable development. It then concentrate on a case stu dy of one of the sustainable success environmental parks in Abu Dhabi (Al Ain park) as a model for environmental and identify the advantages to find out extent of application of each to sustainable development criteria in order to get cleaner and green environment in the future follow the highest standards of sustainable development.
\end{abstract}

KEYWORDS: Sustainable Development, Environmental sustainability, indicators of sustainability, urban parks, sustainable parks, elements, standard, levels of urban parks.

\footnotetext{
*Associate professor Faculty of engineering, Helwan university
} 


\section{INTRODUCTION}

The urban park movement had objective to increase life quality in the modern City. In the last years is noticed an increasing interest for development of nature in Cities. In order to exemplify the importance of urban parks for sustainability and the future of the city. This paper Analyses a project that marked the urban park movement- the alain wildlife park in Abu Dhabi-which play in ecological, social and economic sustainability and it will address the importance of urban green spaces for life quality and sustainable development.

\section{THE PROBLEM OF THE FRESEARCH}

The most of the urban parks suffering from Problems like social, economic and environmental problems which affect the society and impede its continuity of the urban development fulfillment such as lack of attention, poor maintenance, lack of development, underutilization and lack of activities and basic utilities. It was necessary to apply new entries for the development of urban parks that insure the continuity. Can we really pursue sustainable economic growth without harming our societies and the environment? And if we pursue prosperity today, are we condemning our children and grandchildren to poverty tomorrow?

\section{THE HYPOSIS OF THE RESEARCH}

Urban parks are now viewed as an important part of the broader structure of urban Development rather than just recreation and leisure facilities. By integrating conservation, education, residential areas and commercial enterprises within the development for economically sus tainable and controlled growth.

\section{SUSTAINABLE DEVELOPMENT}

The idea of sustainable development grew from numerous environmental movements in earlier decades. Summits such as the Eart h Summit in Rio, Brazil, 1992, were major international meetings to bring sustainable development to the mainstream. The concept of sustainability means many different things to different people, and a large part of humanity around the world still live wit hout access to basic necessities. "Sustainable development has been defined in many ways, but the most frequently quoted definition is from Our Common Future, also known as the Brundtland Report " ${ }^{[1]}$ Sustainable development is development that meets the needs of the present without compromising the ability of future generations to meet their own needs. It contains within it two key concepts:

- The concept of needs, in particular the essential needs of the wo rld's poor, to which overriding priority should be given.

- The idea of limitations imposed by the state of technology and social organization on the environment's ability to meet present and future needs

\subsection{The Goal of Sustainable Development}

The goal of sustainable development is to enable all people throughout the world to satisfy their basic needs and enjoy a better quality of life without compromising the quality of life of future generation. (fig.1) 

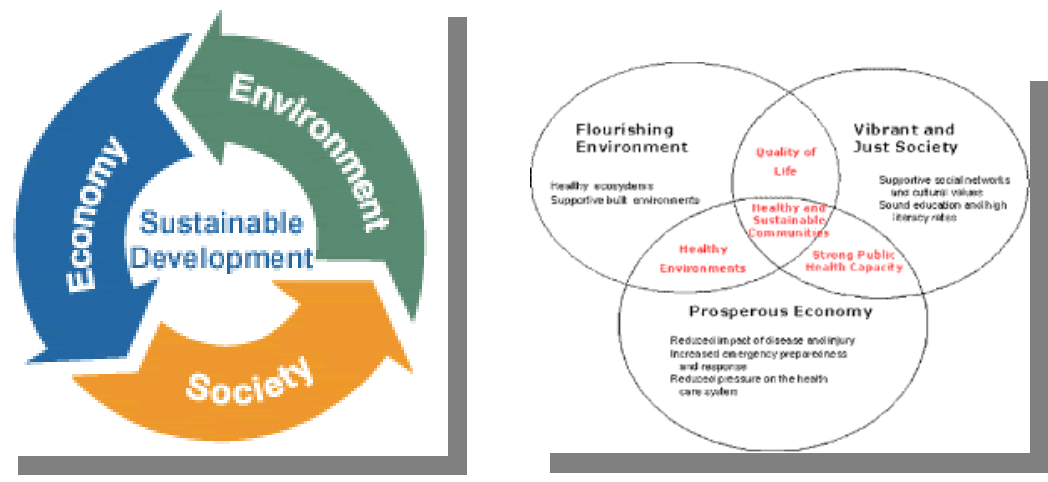

Fig.1 the goal of sustainable development

In urban planning, as in oúner proié ssions, this nas meant a new recognition of how environmental and social aspects of development need to be integrated with economic development, as well as meeting basic human needs for the poorest parts of the world. Because of the dominance of cities and towns. The term sustainable development means that builders, architects, designers, community planners, and real estate developers strive to create buildings and communities that will not deplete natural resources. The goal is to meet today's needs. [2]

Economists have since focused on viewing the economy and the environment as a single interlinked system with a unified valuation methodology. The achievement of sustainable economic development requires a new and different approach to policy making and its implementation. The planners looking for greater integration and co ordination of policy making and its implementation across the public sector, and across social, economic and environmental policy portfolios.

\subsection{Economic Sustainability}

Economic sustainability is the term used to identify various strategies that make it possible to utilize available resources to best advantage. The idea is to promote usage of those resources that is both efficient and responsible, and likely to provide long -tem benefits. With economic sustainability, the goal is to establish profitability over the long-term. A profitable business is much more likely to remain stable and continue to operate from one year to the next [3]. From this perspective, economic sustainability can be seen as a tool to make sure the cities does have a future and continues to contribute to the financial welfare of the owners, the employees, and to the community where the city is located.

- $\quad$ The main types of recreational open space are

- Parks

- Linear open space

- Amenity space within housing areas

- Natural/informal open spaces

- Ornamental gardens

- grassed sitting out areas.

We will concentrate on the urban parks as a tool for sustainability . 


\section{DEFINITION OF URBAN PARKS}

The park is a well-used place. People of different ages, genders, and backgrounds use a park on a regular basis during all parts of the day, week and year. A good park is visible and easy access by various means of transportation. A park should be comfortable, with a good image and possess such amenities as seating, information, food concessions, bike racks, and bulletin boards [4]. These elements make a park not only attractive but enticing for people of all ages. Most of all, a park should be a sociable place where people go to observe the passing scene, meet friends, and interact with a wide range of people different from themselves. Parks have long been recognized as major contributors to the physical and aesthetic quality of urban development.

\subsection{Youth Development}

Parks can provide wonderful opportunities for children of all ages to build the skills and strengths they need to lead full and rewarding lives. The latest thinking about youth development makes a powerful case that children and adolescents are best served by a constellation of community -based activities that helps them build essential skills, knowledge, and aptitudes. The assets children and youth need for healthy development fall into four major domains: physical, intellectual, emotional, and social . And parks can offer programs that are not only fun, but also help them acquire assets in one or more of these domains.

\subsection{The New Vision for Urban Parks}

The "new view" of urban parks calls attention to the broader contributions they can make to the vitality of communities and their residents.

These contributions include [5]:

- helping youth chooses rewarding paths to adulthood by providing programs and opportunities to build physical, intellectual, Em otional and social strength.

- Helping new entrants to the workforce find productive jobs by offering decent, entry level employment opportunities in the community.

- helping community residents improve their health by providing a place to enjoy fresh air and exercise.

- helping citizens join together to make their communities better, by encouraging them to participate in park planning and management.

But a new, broader view of parks has recently been emerging. This new view goes well beyond the traditional value of parks as places of recreation and visual assets to communities, and focuses on how policymakers, practitioners, And the public can begin to think about parks as valuable contributors to larger urban policy objectives, such as job opportunities, youth development, public health, and community building. But that, to do so, they need reliable information about community needs and the effects of actions intended to meet those needs. The brief concludes with a discussion of how public support for parks increases as they expand their role, creating a self reinforcing process.

- Three general attributes of this new kind of park

- Self-sufficiency in regard to material resources and maintenance.

- Solving larger urban problems outside of park boundaries. 
- Creating new standards for aesthetics and landscape management in parks and other urban landscapes. It also explores policy implications of these attributes regarding park design and management, the practice of landscape architecture, citizen participation, and ecological education.

\section{IDEAL PARK ELEMENTS}

- Access and Circulation - a park should allow people alternative choices of movement to provide physical permeability.

- Visibility - a park should also allow for visual permeability allowing people to see in and out of an area.

- Lighting - Lighting improves the night time legibility, use, and enjoyment of a site.

- Diversity - Parks should provide variety in physical features, activities, and users.

- Signage and park information

- Discourage Isolation encoura ge sociability

\section{SUSTAINABLE PARKS}

Urban parks are now viewed as an important part of urban and neighborhood Development. While most of the world has recognized the Theoretical and Empirical Researches in Urban Management Sustainable parks are the new wave in park development. (fig.2) and the trend toward sustainable park development that is taking place across the nation and the world [6].

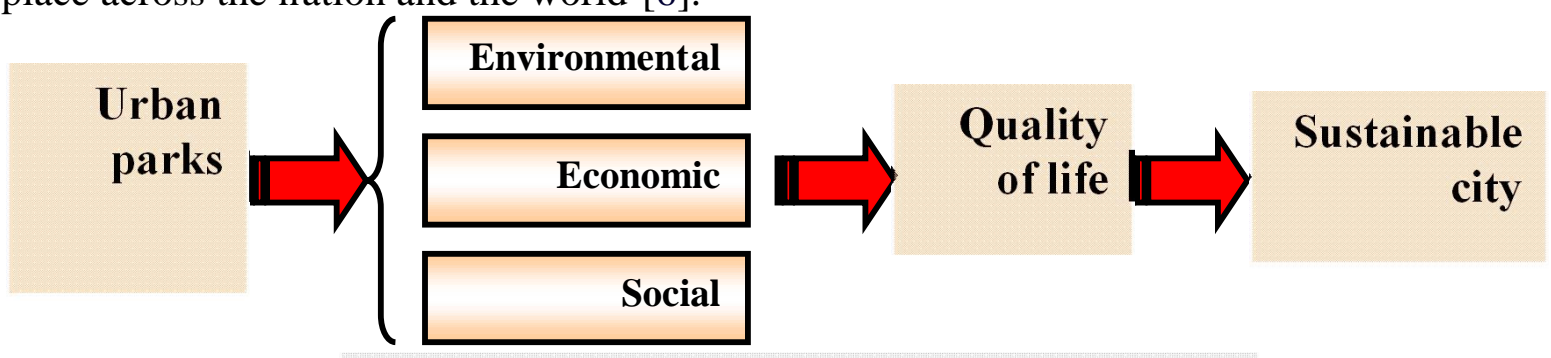

Fig.2 urban parks as a tool for sustainability

\subsection{What is a Sustainable Park?}

Sustainable Parks differ from traditional parks in regard to many details and at least three general principles.

- Sustainable Parks attempt to become self-sufficient with regards to material resources.

- Sustainable Parks can play a role in solving larger urban problems out side their boundaries when they are integrated with the surrounding urban fabric. New aesthetic forms emerge for parks and other urban landscapes.

- Some of the more specific characteristics of Sustainable Parks that may or may not be incorporated into the de Uses green building techniques such as solar power, rain water reuse/greywater for irrigation, etc. to minimize ecological costs of construction and ongoing use sign and management include [7].

- Employs best management practices to ensure healthy ecosystems, e.g. river buffers, using native, non-invasive environmentally appropriate plant choices, etc.

- Encourages partnerships with other entities to foster community support .

- Has a strong sense of place and identity. 
- Recycles waste products as much as possible.

- Enhances the environment, does not degrade it.

- Builds community, relationships, trust and goodwill .

- Educates the public about the value of natural resource stewardship .

- Enhances wild life habitat.

\section{THE FACTORS OF SUSTAINABLE PARKS}

There is an interrelationship between social, economical and environmental factors in relation to urban parks development. Physical factors were also considered key to understanding park utilization and development. This conceptual framework was used as a basis to identify the link between demographic characteristics and park utilization. It integrated the important aspects of the urban parks in terms of social, economic and environmental development. Altern ative uses of parks, the users, the determinants as well as the factors affecting the parks. This conceptual framework asserts that one must consider the interplay of several factors in order to understand parks and social economic development of parks.

\subsection{Economic Factor of Sustainable Parks}

The economic benefit of parks helps to raise property values, create quality townscapes and therefore, build business and community confidence. The quality of parks provides a quick and highly visible indicator of wh ether an area is an attractive place for people to live and for economic activities to thrive. The potential of parks in enhancing and contributing to the changing economies of towns and cities should therefore underpin regeneration programs .

Sustainability is an important concept for today's planners and an increasingly enlightened public especially in connection to social and economic development. Sustainable economic development occurs when progress towards environmental and social sustainability occurs within available financial resources securing such resources may in the Sustainable development recognizes the interdependence of environmental, social and economic systems and promotes equality and justice through people empowerment and a sense of global citizenship [8].

\subsection{Social Benefits of Urban Parks}

Capacity to work together to achieve shared goals, can reduce crime and disorder even in very poor Communities, the urban parks can play a unique role in building the Relationship that constitute social capital. Good quality parks can provide opportunities for voluntary and community activities that can benefit the less fortunate in the society. Well-managed parks can therefore create welcoming environme nts for vulnerable groups like children and wheelchair users, helping them to socialize and take part in community life. Parks help to build community cohesion by getting people to engage with each other in partnerships. In terms of equality for all sector $\mathrm{s}$ of society, free access to parks offer a uniquely affordable alternative to commercial leisure activities [9].

\subsection{Educational and Health Benefits of Urban Parks}

Parks are increasingly used as an outdo or classroom for school subjects such as environmental studies and provide valuable venues for research projects. As a result, they can help rekindle the relationship between urban residents and the natural world. 
Urban Parks provide an opportunity for re search partnerships with universities, scientific and industrial research organizations to examine a wide range of biophysical, economic and cultural issues related to park and visitor [10]. They can also provide work experience and learning opportunities in environmental management and educational opportunities. Urban Parks therefore if well established can serve as laboratories for biologists, geographers, environmentalists as well as social scientists.

\subsection{Environmental and Ecological Benefits of Urban Parks}

Urban areas need to be drained to remove surface water, but the impermeability of many built surfaces raises the probability of flash floods. Urban green protects soils and moderates harsh urban climate for example by cooling the air, reducing wind speed and giving shade.

Healthy environments lead to healthy economies and societies. Parks are pollution ameliorators and help counter the pollution, which can make cities unbearable and unsustainable. Urban parks with well maintained vegetation act as physical filters helping to reduce air pollutants such as sulphur dioxide and nitrogen oxide. They also help in reducing the rate of ozone production and in capturing dusts and volatile organic compounds [11].

Urban parks with tree vegetation are a major contributor to stabilizing the urban climate, they serve as lungs for towns and cities and counter pollution by removing particulates from the air, adding oxygen and removing carbon dioxide from the atmosphere They promote the idea of ecologically sensitive towns and cities by providing wildlife corridors and are havens for many birds, animals and wildflowers. The research will concentrate on one of the mos t successfully models for urban parks alain wildlife park, as a good model for the integration of social, economic and environmental development as well as the factors affecting the parks to achieve economic urban development.

\section{ALAIN PARK}

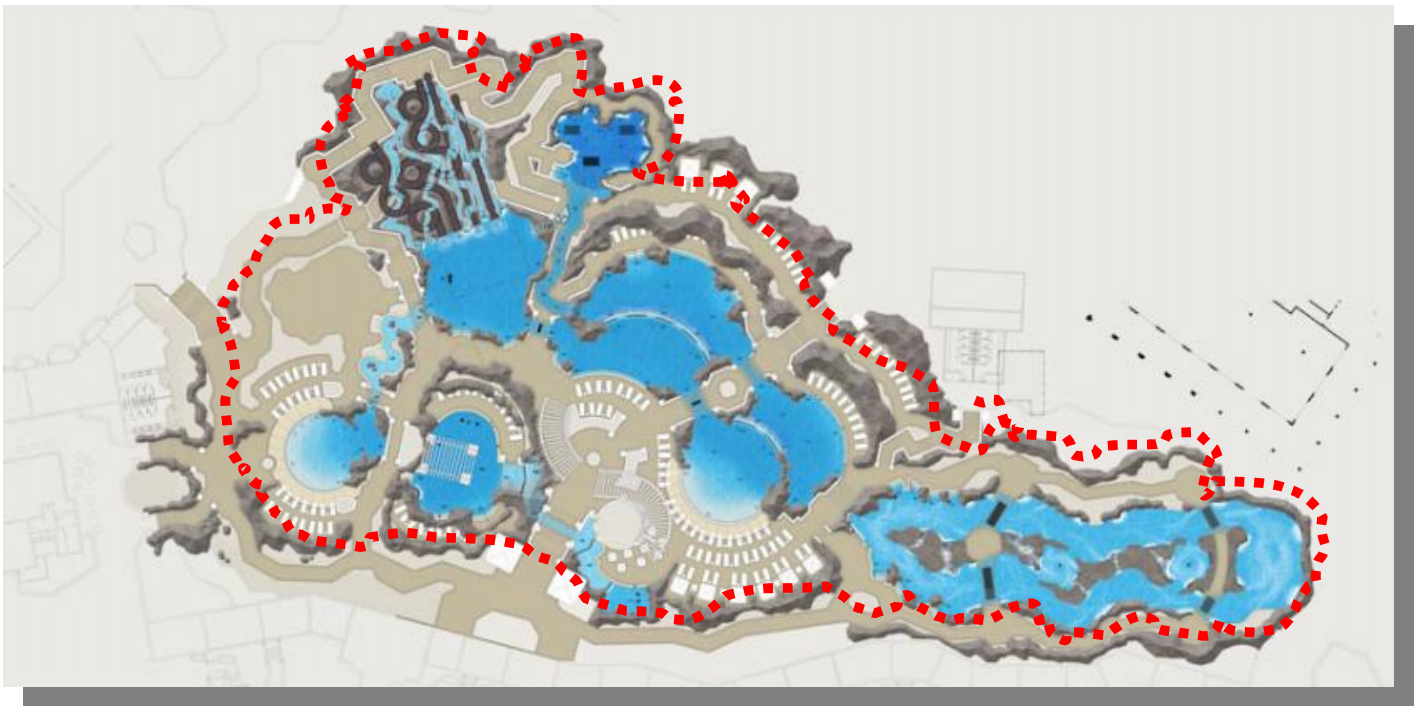

Fig.3 layout of Alain Park 
In a unique desert setting on the edge of Al Ain, a historic oasis settlement in the United Arab Emirates, the Al Ain Wildlife Park \& Resort is a place for people to come and learn about arid land wildlife and conservation through vivid, first $h$ and experience.(fig.3) The Al Ain Wildlife Park \& Resort is based around the current Al Ain Zoo that was founded in 1967 by the late Sheikh Zayed. Since its founding, the zoo has been a centre for endangered species' conservation and is internationally recognized for the successful breeding of desert antelopes.

\subsection{The aim of Alain Park}

The aim is to evolve the resort (AWPR) into a showcase for sustainable living in harmony with nature and wildlife that will be known all over the world. As well as creating a highly attractive destination, and committed to the increasingly important and never ending scientific challenge of conserving desert animal and plant life [12]. The Al Ain Wildlife Park \& Resort will showcase the biodiversity of the world's deserts and demonstrate sustainable desert living. This new wildlife park is part of the UAE's commitment to wildlife conservation both within the UAE and internationally.

\subsection{Master Plan}

The overall vision of the Al Ain Wildlife Park \& Resort (AWPR) is to build a world famous showcase of desert life and culture in Al Ain, in a manner that is sustainable, sensitive and true to the spirit of the region's traditions and cultures.

So the guidelines and master plan for the resort have to entwine the strictest principles of wildlife conservation and environmental sustainability with the most intelligent modern practices in planning and integration. The big challenge was to unify and balance all the various features, requirements and design elements, which inevitably meant resolving some occasional conflicts of interest, while at the same time encouraging innovation and choice.

\subsection{The new vision of Alain Park}

Set in the heart of Al Ain, the Garden City of the United A rab Emirates, extensive works are currently underway to transform the Al Ain Zoo to Al Ain Wildlife Park \& Resort by expanding exhibits and improving facilities are turning the former zoo into a world wildlife park and resort. (fig.4) The UAE continues its dynamic transformation into a booming economic and tourism hub, a mixed use development has been planned and designed, creating a world class, sustainable leisure and learning destination with a wealth of opportunities for the astute investor or developer.

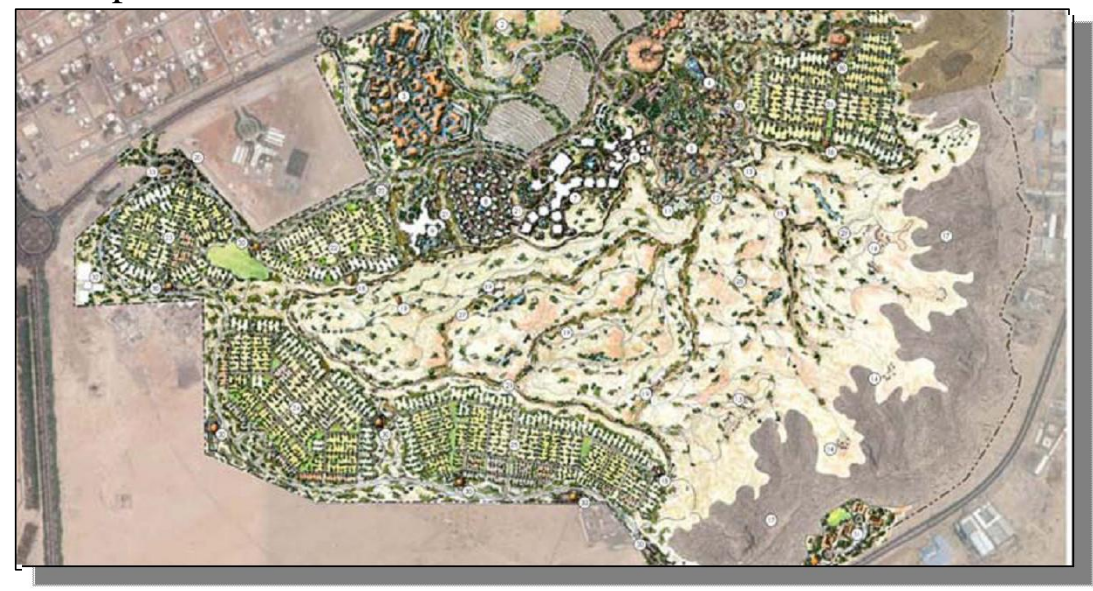

Fig. 4 master plan of Alain Park 


\subsection{The Main Concept for the Park}

Integrating conservation, education, residential areas and commercial enterprises within the development for economically sustainable and controlled growth. Sustainability is a core principle of the Al Ain Wil dlife Park \& Resort and is followed closely in the design, construction and operation of the development. The debris from on-site building demolition is being recycled and reused in construction materials. On the construction site, hundreds of existing tre es are being temporarily relocated until each can be transplanted into the landscape wh en the development is complete.

\subsection{The Elements of the Project}

The project will be made up of several components; a crowning jewel is the Sheikh Zayed Desert Learning Centre which will focus on the desert living experience. The park will also include wildlife safaris; a world deserts zoo and botanical gardens, resort hotel, as well as residential areas. A conservation and breeding centre will also be integral to the park. (fig.5)

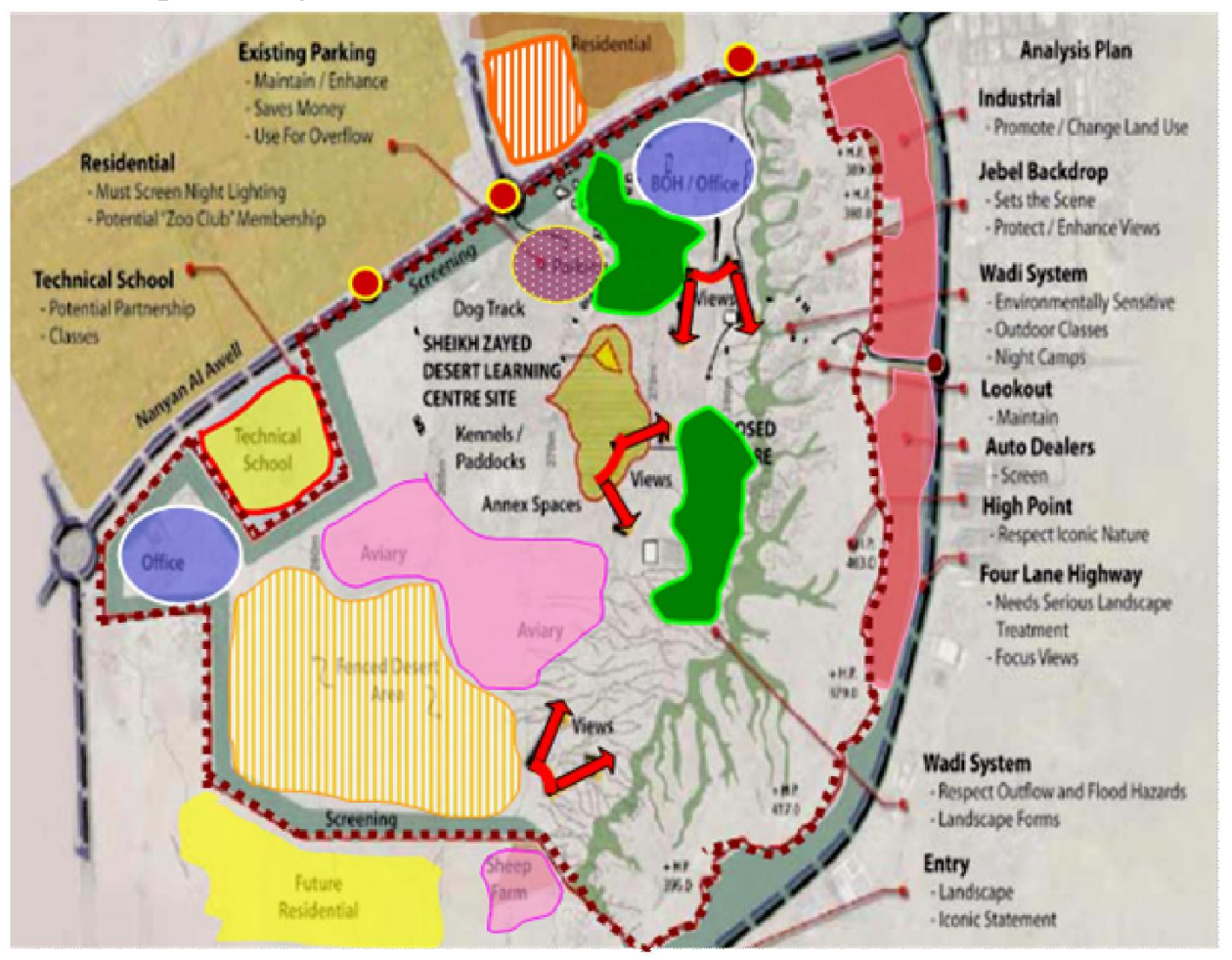

Fig. 5 the elements of Alain Park

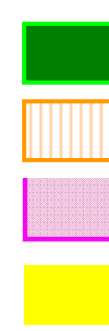

Core zoo

Fenced desert

Aviary

Future residential

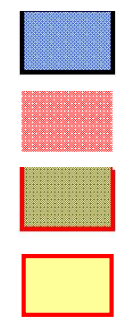

\section{Offices}

Industrial

Learning center

Schools 


\subsubsection{Sheikh Zayed desert learning center (education):}

To create a unique destination attraction that will honor the legacy of Sheikh Zayed and his visionary attitude towards the environment, wildlife and conser vation. Project Description the Sheikh Zayed Desert Learning Centre is an integral part of the development of the Al Ain Wildlife Park \& Resort. The Centre will be an exhibition and exploration of the natural and cultural history of the Arabian Deserts, as well as deserts worldwide. The building is an accessible sculpture that affords multiple spatial experiences [13].(fig.6) A kinetic architectural promenade gives the building its ultimate form, a sculpture that responds to the imposing mass of Jebel Hafeet, a theatrical backdrop to the wildlife park. The idea of geographic Strata has been expressed through the building's system of ramps and multiple Levels. Nestled into the land and plantings, the building further emulates the natural world.
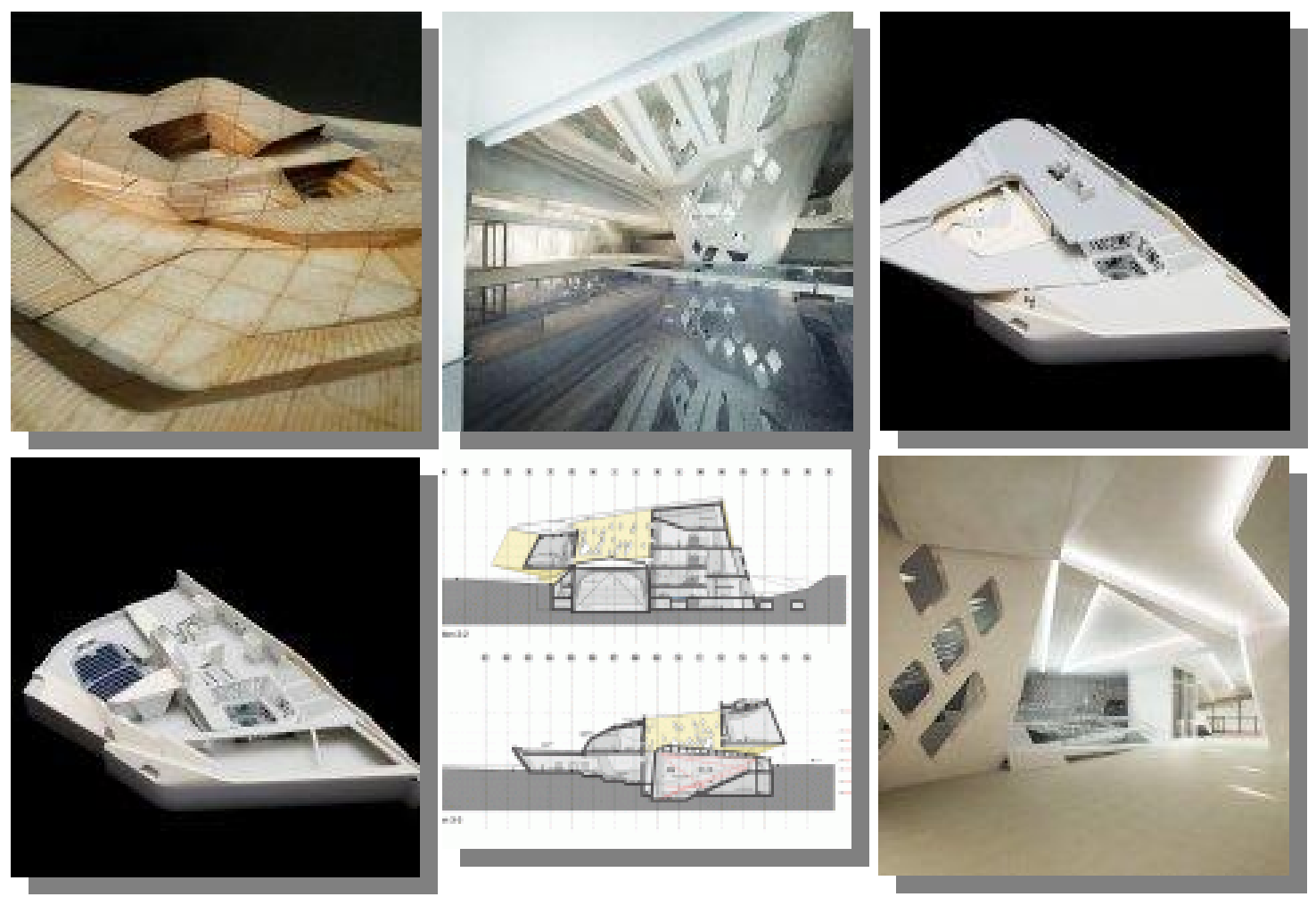

Fig.6 Llı Slıeiklı Zayed DeseıL Leadıing Centıe

Among the first components to be delivered in phase one will be the Sheikh Zayed Desert Learning Centre, which is set to become a premiere example of Estidama's high environmental standards due to its combination of active and passive energy efficient systems. The center will comprise a 10,000 square meter natural history museum focusing on the adaptation of life to the extreme climate of the desert environment. In addition, the geology, paleontology and anthropology of the UAE and arid land environments will be exhibited in an interactive and technologically advanced museum. Once completed; the $\mathrm{Al}$ Ain Wildlife Park \& Resort will become an international reference for conservation, education, and sustainability 

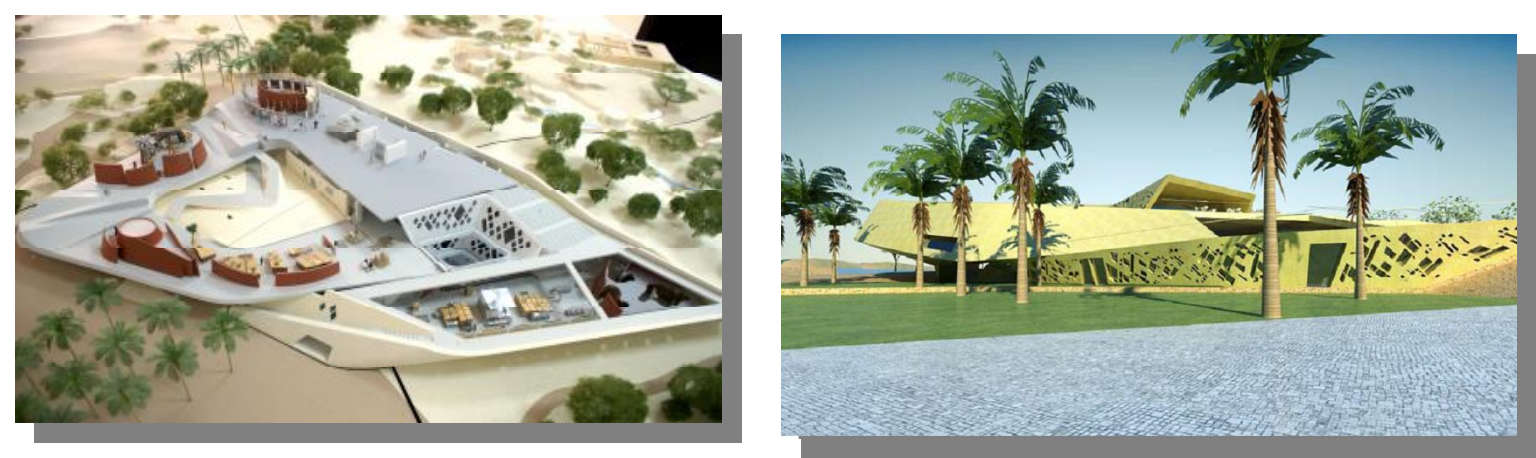

The inclusion of endangered and indigenous wildlife, themed desert safaris, and an exotic mix of botanical gardens and plant collections within the development will provide a centre for learning excellence, in line with the Urban Frame work Plan for Abu Dhabi 2030.

\subsubsection{Conservation}

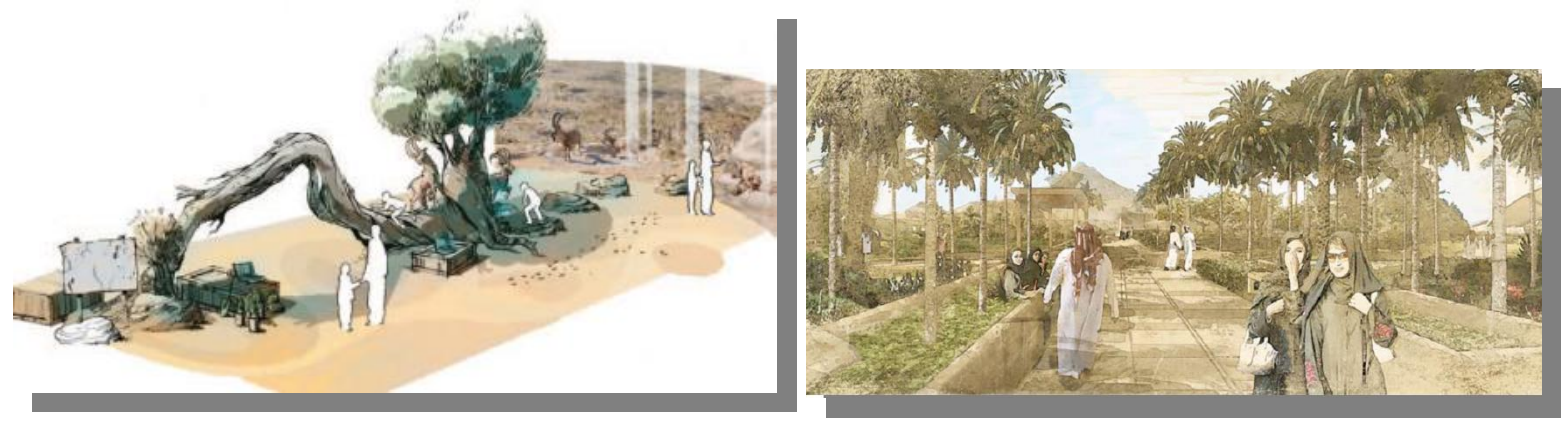

Fig7 the conservation in a unique natural desert

The Al Ain Wildlife Park \& Resort is a place for people who want to experience and learn about wildlife and conservation in a unique natural desert setting whether for a day, a week or a lifetime. It offers a unique leisure, learning and living experience founded on a vision of harmonious and respectful living with wildlife and nature the Al Ain Wildlife Park \& Resort is deeply rooted in the cultural heritage and val ues of the Abu Dhabi Emirate.AWPR's renewed mandate focuses on engaging local people, especially families, in natural immersive surroundings where they will discover the desert and the traditions of people living harmoniously with this place. (fig.7) The Park is divided into distinct areas, e ach with their own experiences: five distinct world desert zoos, conservation and breeding centre, safari experiences and overnight safari encampments, as well as economic ventures including a resort hotel, retail development and residential homes [14].

With conservation in mind, this 800 -hectare project is incorporating leading edge technologies in sustainable design. Every building on site is designed to have lowest environmental impact possible. Retail and resort hotel development will provide economic support to the Park, ensuring that AWPR's conservation and education facilities are maintained well into the future. 
It designed to encourage both the preservation of natural heritage, and the intangible cultural heritage of his people, for today and for generations to come.

The Al Ain Wildlife Park \& Resort is undertaking a multi -billion Dirham development to transform the area of the core zoo into a recreational facility displaying desert habitats of Africa, Arabia and Asia, and will offer luxury resort accommodation, themed retail outlets and tranquil residential communities for sophisticated people who want to experience and learn about wildlife and nature. Conservation is among the founding principle s of the Al Ain Wildlife Park \& Resort, and it has close conservation partnerships with the Environment Agency - Abu Dhabi, San Diego Zoo, World Association of Zoos and Aquariums, and World Wide Fund for Nature. The Al Ain Wildlife Park \& Resort actively p articipates in conservation efforts throughout the world.

\subsubsection{The Residential Areas}

The residential community within the Park will deliver to residents and visitors a completely new way of living. Wildlife, ecology and the environment all co -exist with sustainable practices to create a living environment in harmony with nature.(fig.8) building a residential community that borders the themed desert areas and wildlife means providing an environmentally-friendly and sustainable living environment. The building of this community will include land use, development and community design techniques that preserve natural features [15].
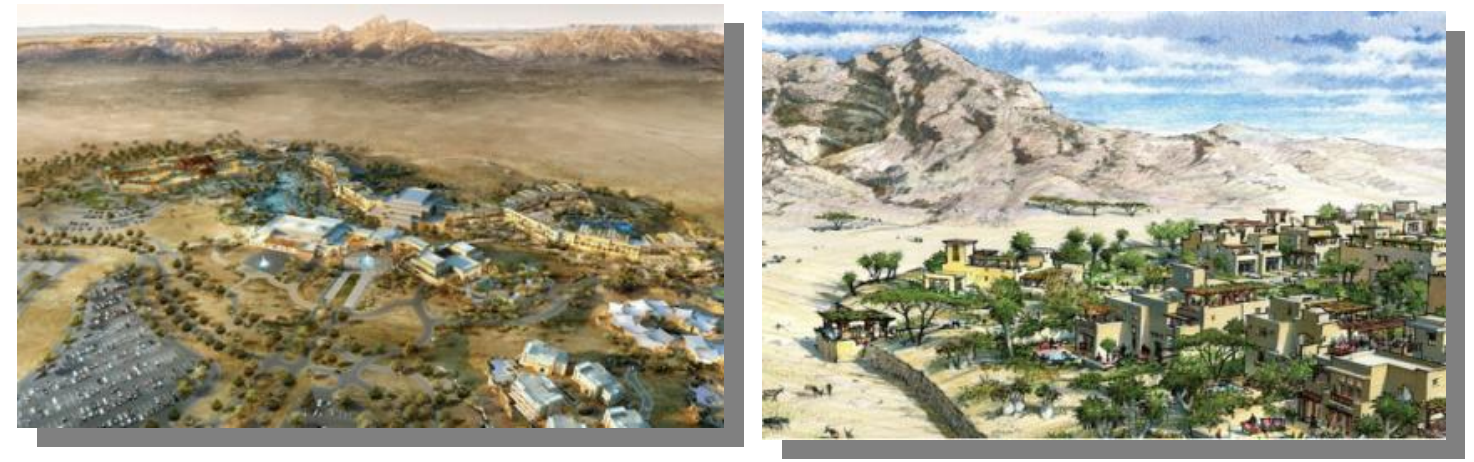

Fig.8 The residential community in Alain Park

Various accommodations will provide visitors the choice of a tamily or iented hotel and a luxurious 5-star resort. All with convenient access to excellent shopping and an oasis theme water park as well as stunning vistas of the Jebel and the wildlife park. Green hotels are environmental-friendly properties which implement practices and programmes that save water and energy and reduce solid waste to help protect the earth. The aim of the Green Hotel Building Guidelines is to reduce the environmental impact of buildings and other supporting systems, without sacrificing comfor $\mathrm{t}$ and health or aesthetics. To be more sustainable, green buildings use primarily available, renewable, reused or recycled materials. The use of rapidly renewable materials is the main focus in the process of building .In addition to relying on natural bui lding materials, the emphasis on the architectural design is heightened. The orientation of a 
building, the utilization of local climate and site conditions and the emphasis on natural ventilation through design considerably reduce operational costs and po sitively impact the environment. The guidelines' main objectives are minimizing the ecological footprint, on-site handling of energy acquisition, on-site water capture, alternate sewage treatment and water reuse.

\subsubsection{The commercial areas:}

A themed shopping environment and multi-level retail area will include outdoor shopping promenades, a shopping mall, cafes, restaurants and special 'dini ng with a view'opportunities. The core zoo and its expanding exhibits and themed desert safaris will provide a centre of excellence that welcomes people of all ages and nationalities to gain a deeper understanding of desert environments from around the world and wildlife that inhabit them.(fig.9) The building considers a valuable resource for generations to come. The close proximity to natural wildlife provides an outstanding backdrop from which to relax, contemplate, and observe animals in their natural settings. This can be done whether you are shopping in the themed retail complex, enjoying fine dining, or indulging in a spa treatment at the hotel. The new core Zoo is a compact area that's easy for families to walk around. It's filled with exciting displays of desert animals featuring exhibit zones of the world's great ocean -edge deserts.
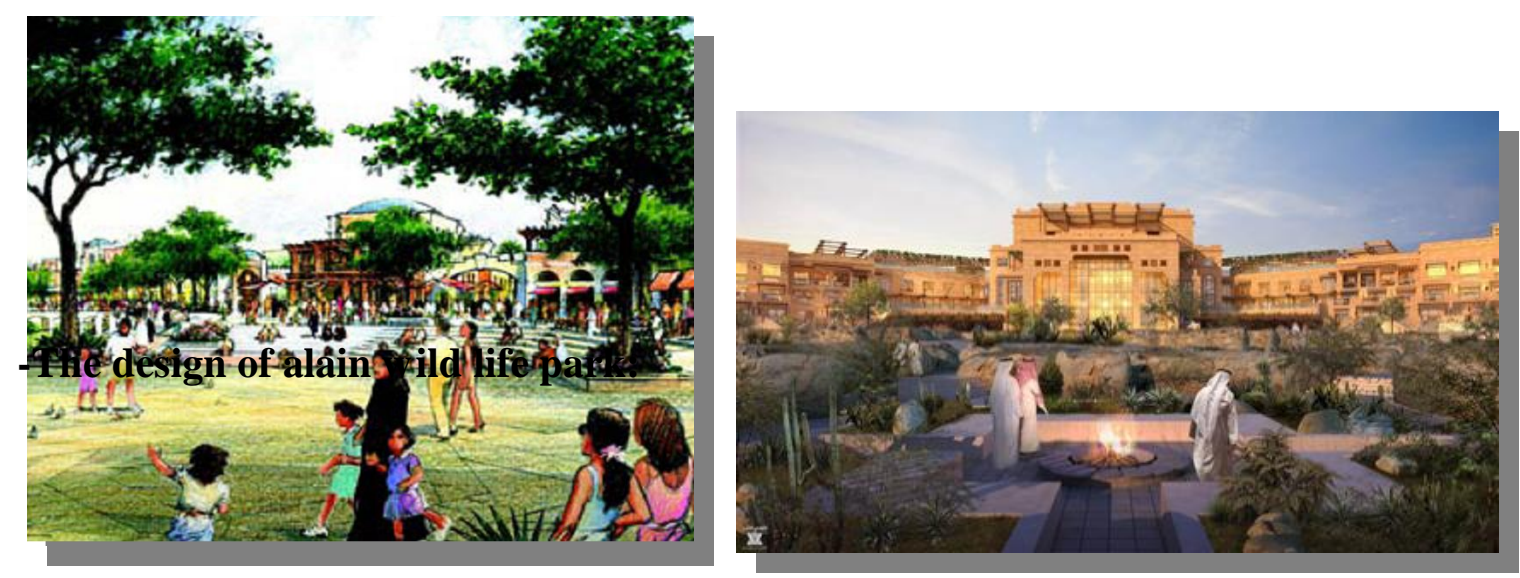

Fig.9 the commercial areas in Alain Park

- the design based on the principles of "New Urbanism" draws inspiration from European Plazas, squares and the residential built form

- A hierarchy of green spaces defined by a variety of parks, plazas, recreational greens binds the community together and encourages alternative modes to transport

- Use of materials with a high recycles content .

\section{CONCLUSION}

The Al Ain Wildlife Park \& Resort consider a model for cultural and ecological sustainability,conservationandeducation .

It is a multi-faceted development designed around wildlife to create an outstanding sustainable leisure and learning destination aimed at bringing people in touch with nature. "Al Ain Wildlife Park \& Resort is the beneficiary of a rare, clear vision of how 
the environment, people and wildlife can co-exist in a sustainable and viable manner. It is based on the ideas of conservation and education, what we term ' $\mathrm{L}$ eisure. Learning and living. One of the unique feature and quality of the project is the fact that investors and residents will directly contribute and be part of supporting wildlife conservation efforts and community development in UAE and abroad.

\section{REFERENCES}

1. World Commission on Environment and Development (WCED), "our common future", Oxford, Oxford University Press, p. 43 , 1987.

2-D. Barry, Stephen Bass," Sustainable Development Strategies", OECD Publishing, 2002.

3- Spence, M.," The Next Convergence, The Future of Economic Growth in a Multispeed World, May, 2011.

4- Crompton, J.," Parks and Economic Development", (PAS 502), APA Planning Advisory Service, 2002.

5- Walker.," The Public Value of Urban Parks", Urban Institute (UI), June, 2004.

6- Rabare R.S., Okech R. and Onyango G. M., 'The Role of Urban Parks and SocioEconomic Development", case study of Kisumu Kenya, theoretical and empirical researches in urban management, no.3 (12), 2009.

7- Douglas Farr, Sustainable Urbanism: Urban Design with Nature ,November 16, 2007

8- Alexander Garvin, Gayle Berens, Christopher B. Leinberger, Urban Land Institute, Trust for Public Land (U.S.), Urban Land Institute, 1997.

9- Cranz, G., Bolan, M., "Defining the Sustainable Park: A Fifth Mod el for Urban Parks, Geography Papers , Landscape Journal, 2004 Volume: 23, Issue: 2, Pages: 102120.

10- Byler, T.," Designing In the Green: An Approach to Sustainable Park D esign", ASLA, LEED AP, Moore Iacofano Goltsman, 2008.

11- Gelb.R.,"Sustainable park development", a beyond-LEED approach to capital program management, public works magazine, 2006.

12- www.alaintimesuae.com.

13- Al Ghalib, E.," Al Ain Wildlife Park Seeks Interns", The National Journal, 2011.

14 -http://www.bartenbach.com

15- Norman." Zayed and the Dream: London Coliseum", London, 2010. 